\title{
Vocational Literacy in Mozambique: Historical Development, Current Challenges and Contradictions
}

\author{
OLEG POPOV and ALZIRA MANUEL
}

\begin{abstract}
The study analyses the historical development of vocational literacy in basic education and Non-Formal Vocational Education (NFVE) in Mozambique, as well as current challenges and contradictions. The theoretical lens of Cultural-Historical Activity Theory (CHAT) is employed in the study. Methodologically the study was executed through an analysis of oral, printed and e-resources produced by the main stakeholders and also the reflective experiences of the authors in their extensive educational work in the country. The findings reveal poorly developed vocational literacy education in schools and non-formal settings in spite of recurrent political declarations about its importance. There is a strong dependence by formal and particularly NFVE sectors on the technical and financial support provided by international organisations. Vocational literacy courses are characterized by a lack of adequate equipment and poor practice. As a consequence, theoretical or elementary forms of vocational knowledge are dominant in the courses, resulting in the dissatisfaction of both learners and educators. Vocational literacy development proved to be a complex field that faces many challenges and is characterised by diverse internal contradictions.
\end{abstract}

\section{Introduction}

The present, past and future developments of social phenomena are always interconnected. It is of great interest therefore to understand developmental trends in different educational fields. This study attempts to provide a historical analysis of vocational literacy in Mozambique. This field is actively developing in the country and is constantly given political attention as it is expected to expand educational and employment opportunities for a broader public

\footnotetext{
(C) 2016 Oleg Popov \& Alzira Manuel. This is an Open Access article distributed under the terms of the Creative Commons Attribution 4.0 Unported (CC BY 4.0) License (https://creativecommons.org/licenses/by/4.0/), allowing third parties to copy and redistribute the material in any medium or format and to remix, transform, and build upon the material for any purpose, even commercially, provided the original work is properly cited and states its license. Citation: Literacy \& Numeracy Studies 2016, 24(1): 4899, - http://dx.doi.org/10.5130/Ins.v24i1.4899
} 
(Ministry of Education 2012). We define vocational literacy here as the activity oriented towards the development of job-related and income-generating knowledge and skills including essential elements of functional literacy and numeracy. For example, a vocationally literate person needs to learn to read and follow instructions, carry out, understand and communicate measurements, and to develop the basic knowledge and skills of a trade. This research is justified by a lack of previous academic studies which systematically explore the development of vocational literacy in Mozambique. This study does not however embrace formal vocational education and training leading to more advanced professional competence.

In Mozambique, vocational literacy is provided mainly by formal schooling through Labour Activities/craft lessons (INDE/MINED 2003) and by different organizations giving short Non-Formal Education (NFE) courses. This latter approach can be defined as deliberate and systematic transmission of knowledge, attitudes and skills provided outside the limits of the formal school (Colletta 1996). NFE can provide opportunities to gain the knowledge and skills necessary to improve citizens' economic and social wellbeing and was one of the focal points of this research. The major research questions are:

- What are the historical trends of vocational literacy development in Mozambique?

- What factors and influences have shaped this development?

- What are the major challenges and tensions in the current development of vocational literacy in the country?

The study is situated in the complex historical context of a developing country, which is briefly presented below.

\section{Mozambique: outline of historical and educational context}

Mozambique gained independence from Portugal forty years ago (1975) and as socialist block countries had actively supported the liberation of the country it chose a socialist post-colonial orientation. Thus, Mozambique became involved in confrontation with capitalist block countries including the apartheid regimes of the neighbouring states of South Africa and Southern Rhodesia, which intervened directly and fuelled military resistance to the socialist transformation in Mozambique, resulting in a sixteen-year-long civil war. The war devastated the country. It caused about one million deaths and over five million people were displaced or made refugees in neighbouring 
countries. Sixty per cent of all primary schools were destroyed or closed (Vieira 2006).

Following the collapse of the socialist block, the Rome General Peace Accord was signed in October 1992 and the country began the change to a free market economy. This resulted in the rapid expansion of the private sector including private educational institutions in the field of formal, non-formal and higher education. A number of private NFE programs began offering courses in English, tourism, management, business, accounting etc., thus marking a transition towards liberalisation and integration into the world free market economy. In 1995 there were only 4 higher education institutions in the country, all of them public, however currently there are 46 higher education institutions (MINED 2013), most of them private.

Today, after more than twenty years of liberal development characterised by an enormous socio-economic stratification of society, Mozambique remains one of the world's poorest countries in 178th place of 187 in the Human Development Index (UNDP 2014). Child labour remains a broadly accepted practice in society where almost 40\% of children are not in school (Casey 2014).

Mozambique's adult population has an average of just 1.2 years of formal schooling, compared to an average of 3.7 years for the least developed countries (Casey 2014). The World Bank, the main promoter of the process of liberalisation of the Mozambican economy, has demanded cuts in public expenses. This has resulted in education in the country remaining largely dependent on foreign funding, with donor assistance accounting for $35.4 \%$ of the total education budget (Bertelsmann Stiftung 2014). In general, school completion rates are very poor with only $63 \%$ of pupils managing to finish grade five. The quality of teaching and poor infrastructure are decisive factors here (Mbele 2005). There is a chronic lack of qualified teachers and the teacher/pupil ratio remains high, at 58 pupils per instructor (Bertelsmann Stiftung 2014). These unfavourable figures concerning the functioning of the public school system help us to understand the importance of Non-Formal Education (NFE) in the country.

\section{Theoretical framework}

Cultural-Historical Activity Theory (CHAT) is used as a framework for analysis of the process of vocational literacy development. Its key concepts are presented and their meaning is defined within the context of the study. Employing a Cultural- 
Historical Activity Theory approach, the study analyses the historical development of vocational literacy in Mozambique, as well as current trends and contradictions.

Activity Theory, developed by Leontiev (1978), is based on the two main theses of Vygotsky. The first thesis is that the sources of personal development are situated in a social environment. Vygotsky (1978) and his followers conceptualised mental development as the transformation of socially shared activities into internalised processes. The second thesis is that human actions, both on the social and the individual level, are mediated by tools, both psychological and physical. These tools are the products of socio-cultural evolution which individuals have access to by being actively engaged in the practices of their communities (Vygotsky 1981). When talking about tools, the researchers refers to external material artefacts as well as to signs, concepts, spoken and written language, stories, diagrams, maps, drawings, internalised mental models, etc.

The mediating artefacts convey a particular culture and history that stretches across activities through time and space. Engeström (1990:264) inferred that they 'insert mankind's historically accumulated and objectified experience into individual actions.’ An important aspect of mediation pointed out by Wertsch (1991) is that mediating tools are viewed as fundamentally shaping and defining the activity. This means that mediating cultural artefacts, such as working tools, instruments, machines, signs, languages and narratives need to be analysed in order to understand any human activity.

Cole (1988) states an important claim that there is no universal, context-free tool. The use of tools implies context specificity. The context of an activity could be defined in general terms as its 'physical and conceptual structure as well as the purpose of the activity and the social milieu in which it is embedded' (Rogoff 1984:2). Popov (2001) has shown that local traditional artefacts can be effective pedagogical tools in teaching vocational literacy in African cultural context.

Thus, following CHAT, it is possible to state that in order to understand an educational activity, it is necessary to pay attention to mediating tools, including narratives, and the context of the activity.

The methodological principles of CHAT 
Engeström (1993) presented three basic principles that can be used to analyse and interpret data that record and describe human behaviour from an activity-theoretical viewpoint. First, a collective activity system can be taken as the unit of analysis. Second, the activity system and its components can be understood historically. Third, inner contradictions of the activity system can be analysed as the source of disruption, innovation, change and development of that system, including its individual participants.

\section{The entire activity system as the unit of analysis}

Vygotsky raised objections to reducing the phenomenon of interest into separate elements that are studied in isolation. He proposed that, for the purpose of analysis, the whole should be partitioned into what he called units. In contrast to atomistic elements, units are designated a product of analysis that contains all the basic characteristics of the whole. According to activity theory, the unit of analysis includes both the individuals and their culturally defined environment (Cole 1981). Rogoff (1995) states, that the use of activity as the unit of analysis, with active and dynamic contributions from individuals, their social partners and historical traditions and materials and their transformations, allows for a reformulation of the relation between the individual and the social and cultural environments in which each is inherently involved in the other's definition. In this study vocational literacy is taken as a unit of analysis.

\section{Historicity as the basis of classification and analysis}

Cultural phenomena are necessarily historical and can be understood only through the historical analysis of their development. Cole (1995:191) explains that 'to understand the workings of culturally mediated behaviour, it is necessary to understand processes of change and transformation that, by definition, take place over time.' Such notions as development and progress should be appropriate for this analysis. Considering the development of complex human activity systems, Engeström (1993:70) suggests that progress in the activity system could be analysed by considering a degree of movement from low complexity and high centralisation towards high complexity and low centralisation. The latter is typical for the case of non-formal vocational education and training development in Mozambique. 


\section{Inner contradictions as the source of change and development}

Activities never take place in isolation. They are interwoven with other activities that deal with the same or connected objects, or produce the instruments used in the activity in question. An activity is not a stable and harmonious system. External influences may change some elements of activities, causing imbalances between them. CHAT uses the term contradiction to indicate a misfit within elements, between them, between different activities, or between different developmental phases of a single activity. Contradictions manifest themselves as problems, ruptures, breakdowns or clashes. CHAT sees contradictions as sources of development. Activities are virtually always in the process of working through contradictions (Kuutti 1996:34). To understand the development of an activity it is necessary to study contradictions existing within the activity system, for example, between the tools currently used and the object created, or the norms that are part of praxis and the division of labour. According to the dialectical philosophy, to develop means to tackle and resolve existing contradictions in the activity system, both intellectually and practically.

\section{The study methodology}

This qualitative study was initially based on desktop document analysis, both printed and electronic. Most of the documents were available only in Portuguese. Document analysis implies constant reading and interpretation of material for the identification of relevant data and its categories. In this process data were organised into categories linked to the research questions (Bowen 2009). Further, as Bowen (2009) suggests, document analysis is logical to combine with other qualitative research methods to ensure triangulation. Thus, in this study structured conversations with different educational stakeholders who have experience of the educational system before and after independence were also used as well as our own reflective experiences of studying and working in Mozambican formal and NFE for many years. This allowed us to connect time, space and instances of human practice in a story describing the complex development of vocational literacy in Mozambique from a holistic perspective. Methodologically, our analytical approach is related to Narrative Inquiry and draws upon the conceptualisation of written and oral narratives and our experiences. This is a rather common methodological approach used in studies of educational experiences. Connelly and Clandini (1990) suggest that the main strength of 
narrative inquiry is in providing 'a sense of the whole.' They explain that the sense of the whole is built from rich data that can be collected in the form of 'field notes of the shared experience, journal records, interview transcripts, others' observations, storytelling, letter writing, autobiographical writing, documents such as class plans and newsletters, and writing such as rules, principles, pictures, metaphors, and personal philosophies' (Connelly \& Clandini 1990:5). In our study many of these techniques were used at different stages of work. The validation of data and resulting inferences was accomplished through the use of independent sources of information. Connelly and Clandini (1990) suggest using the criteria of adequacy and plausibility for validation of the results in narrative inquiry; meaning that persons well familiar with the field might say 'I can see that happening' and we have therefore checked our findings with different educational stakeholders in Mozambique.

\section{Findings}

The selected subheadings or categories structuring the presentation of the findings in the text below were inspired partly by CHAT methodological principals and partly from the analysis of the data.

\section{Dynamic educational field}

The document analysis shows that there are many different providers of vocational literacy in Mozambique. The Ministry of Education and Development and the Ministry of Labour,

Employment and Social Security are major national actors in the field of education and training in general, including adult education and NFE. The Ministry of Education develops and monitors the entire educational system. For example, through the National Office of Literacy and Adult Education it provides the curriculum for literacy programs, the teaching and learning materials, employs literacy educators and promotes vocational skills development in adult education programs. The National Institute of Employment and Professional Training (NIEPT) belongs to the Ministry of Labour, Employment and Social Security and is the main institute responsible for Non-Formal Professional and Vocational Education and Training. The NIEPT organises the training centres and the training programs and provides the certificates and some teaching material. Foreign and local NGOs, private and religious organisations are other important actors working with different kinds of vocational literacy in the 
country. The field of vocational literacy development is rapidly evolving and expanding. Two driving and partly complimentary forces could be identified behind the recent development trends. On the one hand, political pressure to expand the provision of vocational education opportunities for a broader public and on the other hand, the economic interests of non-formal education providers. Private actors can earn good money by offering expensive courses and a market for such courses continues to expand particularly in the cities.

\section{A challenging cultural context for promoting vocational literacy}

Educational development inevitably mirrors and at the same time contributes to the development of the local cultural context. Mozambique, with a population of about 26 million, has a very complex cultural environment. There are 18 major national languages in the country and many more dialects, but the only official language is Portuguese, which is spoken mostly as a second language (Ministry of Education 2012). The largest religion is Christianity, with significant minorities following Islam and African traditional religions. This means that Mozambican society is multilingual and multicultural. After independence a new native social elite was created and new 'modern' values came into conflict with 'traditional' values leading to many challenges in educational development.

Currently in Mozambique there are clear tensions between the values of a modern individualistic society that, for example, prioritises the nuclear family and traditional cultural values where the rules and needs of the extended family are in focus. The role and status of traditional culture has changed greatly in Mozambican society. Before independence the colonial administration marginalised traditional culture. During this period there was a minority of 'assimilated' Mozambicans, who had adopted the Portuguese culture in order to enjoy 'the constitutional rights and privileges of Portuguese citizens' (Ferreira 1974:18), and a majority of 'non-assimilated' Mozambicans who maintained their traditional culture and were deprived of such rights and privileges.

After independence, the national government encouraged the reinvigoration of some traditions, such as folklore, but maintained an orientation towards state-driven cultural unification and a socialist modernization of society. Thus, the use of local languages in educational institutions was discouraged, since Portuguese was considered the language of national unity. This situation is still fresh in the memory of all educational stakeholders and those who attended 
schools during these times. Even service personnel were discouraged from using local languages in school premises.

Nowadays, it is possible to witness a strengthening of traditional cultural influences in society in general. The use of local languages is encouraged in primary education and adult literacy courses, and vocational literacy courses in Mozambican languages are also promoted by some NGOs. According to political avowals, all major Mozambican languages will be used in formal education to support the development of basic literacy skills. However, this demands significant investment in the development of learning materials and teacher training, which appears to be problematic to achieve without massive donor support, as was recognised by our informants.

Multiculturalism in Mozambique has another subtle social tension - between the official endeavour to achieve national unity and the valorisation of local cultural traditions leading occasionally to regional separatism. This issue is very sensitive and periodically appears to have explosive character resulting in paramilitary actions in the centre of the country.

Cultural complexity needs to be seen in a historical perspective. Thus, in order to understand the development of vocational literacy we need to pay attention to historical changes in the socio-cultural context and tensions caused by them in the educational activity system. This can be clearly seen in the description of the historical evolution of vocational literacy in formal schooling.

\section{The historical development of vocational literacy in the school system}

As was mentioned earlier, after independence in 1975, the country was politically oriented towards socialism. During this period hopes for a better life through education for all were high. The socialist-oriented government made a great effort to promote general education and mass literacy. However there were many hidden obstacles preventing the provision of socially relevant education. As one of the interviewed teachers explained 'the failure of practical work in basic education could be attributed to two main factors: the lack of teachers with appropriate knowledge and lack of materials for practical activities.' Thus, the formal education system tended to promote only theoretical types of knowledge without giving children functional skills, values and attitudes to contribute to the development of their communities and to enter the labour market. Due to the 
predominance of theoretical knowledge in basic education as children advanced in the educational hierarchy, their alienation from the manual work practised in traditional communities also increased. This phenomenon has complex historical roots as explained below.

The process of education as alienation from a traditional community had already started in colonial times (before 1975). In that period, manual work was viewed by society as an activity for 'black' people. During the colonial period, the greater part of Mozambican primary education for the indigenous population was carried out by the Catholic, Protestant and Evangelic missions. Many missionary schools had small workshops, farms and nurseries. School agriculture was considered to be an income generating activity for the schools in rural areas, where children used to spend many hours in the fields.

Often these were not only school fields but also the private fields of the class teacher and his family (most of the teachers were male). As one retired teacher commented 'the learners used to work in the cotton fields belonging to the school and after the classes I used to send some of them to work in my own fields'. Hard agricultural work caused some pupils to become fatigued and to dropout from school. Teachers also included domestic work in their homes as extra-curricular activities. One of the respondents said ' $I$ used to select some learners to take care of my children and help in cleaning and cooking at my home'. According to him, these kinds of activities were seen as a privilege by the selected learners and their families because the criteria for selection were based on the children's 'good behaviour' in school.

The so-called rudimentary indígena education, broadly spread in rural areas before independence, included arts and crafts and an elementary level of technical education for the 'natives', in particular for boys. The main objective was to provide education oriented towards manual work. However, in general, apart from the practice of hard agricultural work, many interviewees recognised that during the colonial period elementary schools were giving learners important life skills that are missing in modern times: for example, mending clothes, making tools, cooking, and doing crafts.

With independence, a socialist educational model has been adopted. The Marxist ideological stance of linking theory to practice was included in the official educational policy. Agriculture was made a compulsory extra-curricular activity in every rural school as part of local vocational literacy. In the urban schools vocational literacy was implemented through a subject called trabalhos manuais (manual 
work), in which students could learn different useful practical skills adapted in accordance with the level and age of the pupils. Directly after independence, however, it was difficult for the new government to promote physical labour in schools because for the people it was associated with the evil colonial practices prior to independence. This was also the time of the emerging war with Rhodesia, consequently many rural schools had to dig trenches to hide from expected 'Ian Smith attacks'. Additionally, the practice of re-education camps emerged during the post-independence period, where inappropriate pupils' behaviour was corrected by hard physical work. Thus it is easy to understand why school agriculture and manual work did not have a long life after independence. Other reasons for the gradual disappearance of these activities in the school curriculum could also be that:

- these activities were perceived as being of low social status,

- they did not ensure the pupils' academic success,

- many teachers had no competence or motivation to teach such skills.

With the creation of the National System of Education in 1983, one more attempt was made to introduce labour activities in schools as a compulsory curriculum subject to promote vocational literacy. According to the syllabus developed at that time, the subject comprised a fixed range of manual activities such as metal, wood, paper, clay and agricultural work. However, these prescribed ranges of activities were not related to the conditions and available resources of the school (Jasso, Januário \& Popov 1996). As a result many schools could not accomplish the intended curriculum for labour activities (Popov 2000). Local curriculum initiatives and flexibility was not welcomed in schools at that time. The slogan of 'National Unity' demanded uniformity and equality in all spheres of social life within national frontiers.

More recently (2004), an attempt was made to reinvigorate the subject in the primary school curriculum with the name oficios that suggests the teaching and learning of arts and crafts with relevance for local community life (INDE/MINED 2003). However, in many public schools, teachers just use the time of ofícios as an extended break and to give their pupils the opportunity to do what they want to do. One of the informants said 'At these times I usually tell the learners to go out and play with what they want, because I don't have material for oficios'. Obviously, the problem is not only the lack of material, but it is also related to teachers' skills to work with this 
subject, as teacher training fails in the development of teacher competences for manual activities. Other teachers just use the time intended for manual work classes to help learners who have difficulties in other subjects. One of teachers explained 'I use the time of oficios to work with learners who have problems in reading and writing activities'.

In rural areas, during the lessons of oficios pupils usually work in the school machamba (farm), without any clear instructions or learning tasks. This occurs not only due to the lack of teachers' competence in the subject and lack of resources (Macovela 2014), but also because of the perpetuating perception of the low status of manual work and lack of stimulus for the teachers and schools to exercise initiatives and creativity in promoting vocational literacy.

Document analysis, observations and interviews confirmed that today, 40 years after independence, labour activities such as agriculture, craft, technology, arts or other practically oriented activities promoting vocational literacy exist only occasionally in the day to day practice of Mozambican public primary schools. There is, nevertheless an acute need for this kind of knowledge and skills in Mozambican society, as will be discussed below.

\section{Inner contradictions}

Many contradictions were identified in the development of vocational literacy. We will present just some of them that are particularly relevant in the Mozambican context. One of the major contradictions is the inadequate attention paid to the development of agricultural literacy in the formal and non-formal educational sectors at the same time that there is a continuing social demand for it. More than $75 \%$ of the people in Mozambique depend on agriculture for their livelihood (Bertelsmann Stiftung 2014). Low productivity small holder farmers account for 95\% of the country's agricultural production (Bertelsmann Stiftung 2014). Considerable gains could be made here by improving their knowledge and skills to increase productivity. Formal and non-formal education could make a contribution by providing relevant agricultural literacy skills, at least for the $70 \%$ of the population that live in rural areas. Agriculture is and will continue to be one of the most important sectors of the country's economy. This issue remains a serious challenge for the national education system. The Ministry of Education and Development is failing in their curriculum policy of promoting agriculture in rural schools. One of the reasons could be the complex 
issue of assuring the provision of the necessary resources and materials (mediating artefacts) for school agricultural activities. Related issues are those of accountability and management in the assurance of the purposeful use of the supplies provided. Practical activities cost money and demand logistics that are not currently in place within the formal education system. The contribution of the non-formal sector, mainly through foreign NGOs, is also rather marginal in the promotion of efficient agricultural practices. It is worth noting that the Ministry of Agriculture also disregards the promotion of agricultural literacy through non-formal adult education courses (Luis 2012).

In general, non-formal technical vocational education should include practice and hands-on based courses. However, they are usually characterised by a lack of adequate equipment and poor opportunities to practise skills. Thus, another important inner contradiction between the practical nature of technical knowledge and skills and the absence of the necessary conditions for the realisation of practical activities can be identified. This leads to the domination of theoretical or rudimentary forms of vocational knowledge in the technical courses (e.g. car-repairing or refrigeration) resulting in the learners' and the educators' dissatisfaction. Vocational literacy has a proven impact on employment and self-employment but also on generic life-skills development. Nonetheless, in many cases participants have higher expectations concerning program outcomes than are achieved in reality.

Another contradiction is concerned with learners' desires and opportunities. For young people becoming literate in modern technology use is more attractive than learning agriculture in schools or training centres. However, lack of the necessary resources in school makes computer studies and other kinds of modern technology literacy unrealistic for the majority of pupils in formal education. However relevant, vocational literacy including learning agricultural activities, is rather undesirable as they have seen it only as hard work in the fields giving a very poor income. Non-formal computer courses are too expensive for most young people. Private providers with a good reputation charge about 1700 meticais, equivalent to 35 Euros per month, for six months (over $200 €$ ), which makes them rather inaccessible for the majority of young people.

A similar situation exists also in relation to foreign language studies. English language skills are considered to be important vocational knowledge by many Mozambican people. The country is 
neighbour to a powerful regional economic leader - South Africa and actively involved in regional and global collaboration.

Communication skills in English create new income generating opportunities. Formal primary school education provides limited possibilities to learn English; it is not even included in the curriculum for grades 1-5 in public schools. Private NFE institutions are therefore active in this area and courses are usually very expensive.

\section{Poor professional context}

Educators, teachers and literacy workers are the main actors defining how vocational literacy will be shaped and even if it will be implemented at all. Educational activities in Mozambique are rather teacher-centred. Thus, teacher motivation delimits to a great extent the effectiveness of such activities. In the current liberal economy system monetary remuneration is rather decisive for the teachers' commitment to their work.

In the formal education system, the teachers giving practical activities related to vocational literacy do not receive any monetary benefits in comparison with those who choose not to do any practical components. However any practical activity, for example teaching embroidery, demands extra time to organise the logistics of the process, e.g. asking children to bring the necessary materials from their homes, share materials, etc. The situation is aggravated by the fact that teachers receive almost no instruction or training in teaching crafts and ofícios during their teacher education. In NFE the situation is rather similar. The practical component is weak in most of the NFVE courses.

The poor working conditions are illustrated by the fact that literacy workers in Mozambique currently have a salary of about 700 meticais (about 15 Euros) per month. Contracted by the Ministry of Education and Human Development she or he usually has a contract for a maximum of one year. Salary payment delays of 3-4 months are rather 'normal', according to the collected narratives. Low salaries and high work load is what also faces literacy workers and educators in many NFVE courses. Sometimes literacy workers also teach other courses like sewing or small business management to gain an extra income. However, when such educators have to give classes twice a day (morning and evening) and use the rather expensive transportation system this makes their extra income marginal.

Additionally, we observed that one of the general weaknesses of NFVE is the absence of quality assurance and a support system for 
curriculum implementation. For example, there is no external monitoring of the programs. Educators do not have the possibility to improve their professional competence. There is no pedagogical resource centre for NFVE teachers or functioning centres supporting vocational literacy development. All this contributes to a poor professional context for educators working with vocational literacy.

\section{Discussions}

The development of vocational literacy that enhances learners' job-related and income-generating knowledge and skills, including essential elements of functional literacy and numeracy, can assure the social wellbeing of citizens. Following CHAT methodological principles we considered vocational illiteracy as a unity transecting the compartmentalising borders of formal and non-formal education. This allowed us to get a more holistic picture concerning the provision of socially and individually relevant education. According to the World Education Forum (UNESCO 2000:8), 'all children, young people and adults have the human right to benefit from an education that will meet their basic learning needs, in the best and fullest sense of the term, an education that includes learning to know, to do, to live together and to be.'

Mozambique has experienced rapid economic, social and political changes but unfortunately the current trend of globalisation and its neoliberal policies have increased economic stratification, unemployment, poverty and social exclusion as perceived by the majority of our informants. Formal education, which should respond to these challenges, is characterised by high dropout rates, lack of relevance, as well as insufficient provision mainly in the rural areas. As we have found, vocational literacy is almost absent throughout the formal basic education system. Pupils in schools do not learn practical skills related to possible income generating activities and the satisfaction of their daily needs, such as agriculture, cooking, sewing, carpentry, etc., even if these activities are included in the curriculum for basic education. Therefore, this places extra expectations on nonformal vocational courses that people need to pay for.

Considering a CHAT theoretical stance, we need to reflect on contextual factors affecting human development. In the light of the historical perspective it is possible to state that the context was not only unsupportive but also oppressive for the majority of people during the colonial, socialist and liberal phases of societal development in Mozambique. Poor families in the cities and rural 
areas have had little support to improve their wellbeing through education. The current dramatic increase in the socio-economic stratification of society makes a professional career through education almost equally as problematic as in colonial times for the majority of poorer citizens. Vocational literacy remains the only way for 'ordinary people' to become involved in sustainable, income generating activities.

Mediating artefacts are often needed to create relevant activities. For example, sewing is not possible without a sewing machine. CHAT affirms that mediating tools fundamentally shape and define the activity. If vocational education courses lack basic equipment they cannot provide the necessary skills and competencies for the participants. This is also what we found in our previous research on many NFVE programs in Mozambique (Manuel, Popov \& Buque 2015). Outdated and non-functional equipment is a rather typical phenomenon in NFVE programs. The situation is similar in public schools, in particular those which introduce agricultural activities in the curriculum; the Ministry of Education does not provide the necessary tools or modern seeds and fertilisers to make these activities visibly relevant and appealing for teachers, learners and their parents.

The absence of proper practical components and internship opportunities severely impedes vocational competence development. According to general CHAT postulates, individual development is seen as the transformation of socially shared activities into internalised processes. Without active participation in vocational activities it is not possible to develop the desired individual competence. Thus, we see an acute need to assure and control the implementation of adequate practical activities in vocational literacy courses.

In general, the Ministry of Education (MINED) admits the absence of coordination, quality assurance mechanisms and holistic understanding of the situation with NFE in the country.

Minimum standards and regulatory instruments to assess and certify the different programs on offer are still lacking. There is still no clearly established connection between MINED and other institutions carrying out community (capacity) building activities such as for example, NGOs working in non-formal education and other Ministries (Health, Agriculture, Women and Social Action etc.). (Ministry of Education 2012:73). 
In this context, the Ministry of Education (2012) recognises a need for greater attention to non-formal vocational education programs transmitting professional skills and competencies as well as developing life skills and socially positive behaviours and attitudes.

The imminent exploration of newly discovered natural resources (coal, gas, minerals) in the remote regions of the country with the involvement of large foreign actors, in particular China, opens new demands for vocationally literate people. We can predict the future need for literacy programs that will focus on multilanguage skills and vocational literacy with elements of English and local languages. Vocational literacy in Mozambique is a complex educational activity that faces many challenges, has many contradictions and needs a more systematic analysis and further research.

\section{References}

Bertelsmann Stiftung (BTI) (2014) Mozambique Country Report. Gütersloh, Bertelsmann Stiftung, retrieved 4 March 2015 from http://www.btiproject.org/uploads/tx_itao_download/BTI_2014_Mozambique. pdf.

Bowen, G (2009) Document Analysis as a Qualitative Research Method, Qualitative Research Journal, vol 9, no 2, pp 27-40. doi: http://dx.doi.org/10.3316/QRJ0902027

Casey, J (2014) Understanding High Dropout Rates in Primary School Education in Mozambique, MSc Pease and Development work. Linnaeus University. Sweden.

Connelly, F and Clandini, D (1990) Stories of Experience and Narrative Inquiry. Educational Research Association, vol 19 no 5, pp 2-14. doi: http://dx.doi.org/10.3102/0013189x019005002

Cole, M (1981) Preface, in Wertsch, J, ed, The Concept of Activity in Soviet Psychology, Armonk, M. E. Sharpe, Inc., New York. doi: http://dx.doi.org/10.1016/b978-0-12-179501-6.50006-5, http://dx.doi.org/10.1016/b978-0-12-179502-3.50006-6 and http://dx.doi.org/10.1016/b978-0-12-179760-7.50003-6

Cole, M (1988) Cross-cultural Research in the Socio-historical Tradition, Human Development, no 31, pp 137-157. doi: http://dx.doi.org/10.1159/000275803

Cole, M. (1995). Socio-cultural-historical psychology: some general remarks and a proposal for a new kind of cultural-genetic methodology. In Wertsch, J.V., del Río, P., Alvarez, A, eds, 
Sociocultural Studies of Mind. Cambridge University Press, Cambridge, pp 187-214. doi:

http://dx.doi.org/10.1017/cbo9781139174299.010

Colletta, NJ (1996) Formal, Nonformal, and Informal Education. In

Tuijnman, AC, ed, International encyclopedia of adult

education and training. 2nd ed, Pergamon Press, Oxford, England, pp 22-27.

Engeström, Y (1990) Verksamhetsteori och utvecklande arbetsforskning. Lycksele, Äldrecentrum Norr.

Engeström, Y (1993) Developmental Studies of Work as a Test

Bench of Activity Theory: The case of primary care medical practice. In Chaiklin, S. and Lave, J, eds, Understanding

Practice: perspectives on activity and context, Cambridge

University press, Cambridge, pp 64-103. doi:

http://dx.doi.org/10.1017/CBO9780511625510.004

Ferreira, E (1974) Portuguese Colonialism in Africa the End of an

Era: The effects of Portuguese colonialism on education, science, culture and information, The UNESCO Press, Paris.

Instituto Nacional de Desenvolvimento da Educação (INDE) and Ministério da Educação (MINED) (2003) Plano Curricular do Ensino Básico. Objectivos, Política, Estrutura, Plano de Estudos e Estratégias de Implementação. (Curriculum for basic education), INDE, Maputo.

Jasso, M, Januário, F and Popov, O (1996) Perspectivas do Desenvolvimento Curicular na área de Ciências Naturais e Tecnologia (Perspectives on science and technology education curriculum development), Revista Contacto, 11, pp 12-18. (in Portuguese)

Kuutti, K (1996) Activity Theory as a Potential Framework for Human-computer Interaction Research. In Nardi, B, ed, Context and Consciousness: Activity theory and human-computer interaction, MIT Press, Cambridge, MA, pp17-44.

Leontiev, AN (1978) Activity, Consciousness, and Personality, Prentice-Hall, Englewood Cliffs, NJ.

Luis, R (2012) Youth and Adult Learning and Education in Mozambique, Open Society Initiative for Southern Africa (OSISA), KuaZulu-Natal, retrieved 2 July 2014 from www.osisa.org/sites/.../Mozambique_yale_final.pdf.

Macovela, S (2014) Novo Currículo e as Tecnologias e Ofícios no Ensino Básico em Mocambique, (New curriculum and 
technology and Arts in basic education in Mozambique), retrieved 16 Sep 2015 from www.academia.edu/.

Mbele, N (2005) Mozambique: Towards rehabilitation and transformation. In Akoojee, S, Gewer, A and McGrath, S eds, Vocational education and training in Southern Africa: A comparative study, Human Sciences Research Council, Cape Town, pp 65-75.

Manuel, A, Popov, O and Buque, D (2015) Towards Programme Improvement in Non-formal Vocational Education and Training in Mozambique, Problems of Education in the 21st Century, vol 67, pp 60-71.

Ministério de Educação (MINED) (2013) Dados Estatísticos Sobre o Ensino Superior em Moçambique 2012, Direcção para a Coordenação do Ensino Superior, Maputo.

Ministry of Education (2012) Education Strategic Plan 2012-2016. Ministry of Education, Maputo.

Popov, O (2001) Lokala kulturella artefakter som didaktiska verktyg. (Local cultural artefacts as pedagogical tools), NCM, Gothenburg University Press (Vänbok till Wiggo Kilborn). 137-146. (in Swedish)

Popov, O (2000) Learning from the Everyday Environment: Upper primary school students' understanding of nature and technology in Mozambique. In Malmberg, L-E, Hansén, S-E \& Heino, K, eds, Basic education for all: A global concern for quality, Åbo Akademi University Press, Vasa, Finland, pp 337351.

Rogoff, B (1984) Introduction: Thinking and learning in social context. In Rogoff, B and J. Lave, J, (Eds.) Everyday cognition: Its development in social context, Harvard University Press, Cambridge, MA, pp. 1-8.

Rogoff, B (1995) Observing Sociocultural Activity on Three Planes: Participatory appropriation, guided participation, and apprenticeship. In Wertsch, JV, Del Rio, P, \& Alvarez, A, eds, Sociocultural Studies of Mind, Cambridge University Press, New York, pp 139-164. doi: http://dx.doi.org/10.1017/cbo9781139174299.008

UNDP (2014) Human Development Report 2014. Sustaining human progress: Reducing vulnerabilities and building resilience, retrieved 8 Aug 2015 from http://hdr.undp.org/sites/default/files/hdr14-report-en-1.pdf. 
UNESCO (2000). Dakar Framework for Action, Education for All: Meeting our Collective Commitments. Adopted by the World Education Forum. Dakar, Senegal, 26-28 April 2000, retrived 16 Sep 2015 from

http://www.unesco.at/bildung/basisdokumente/dakar_aktionspl an.pdf

Vieira, M (2006) Educação de Adultos, Analfabetismo e Pobreza em Moçambique, Universidade metodista de Piracicaba, Brazil.

Vygotsky, L (1978) Mind in Society: The development of higher psychological processes, Cole, M, John-Steiner, V., Scribner, S, and Souberman, E, eds and trans, Harvard University Press, Cambridge, MA.

Vygotsky, L (1981) The Instrumental Method in Psychology, in Wertsch, J, ed, The concept of activity in Soviet psychology, M. E. Sharpe, Inc., New York, pp $134-143$.

Wertsch, JV (1991) Voices of the Mind. A sociocultural approach to mediated action, Harvard University Press, Cambridge, MA. 